\title{
A GLOBALIZAÇÃO COMO MEIO DE OCIDENTALIZAÇÃO DO ORIENTE MÉDIO
}

\author{
Ananda Vilela da Silva Oliveira ${ }^{1}$
}

\begin{abstract}
Resumo: A partir do conceito de globalização perversa de Milton Santos, esse artigo analisa a tentativa de ocidentalização do Oriente Médio que utiliza instrumentos econômicos e culturais para expandir as fronteiras do capitalismo. Para isso, serão utilizados dados históricos para uma análise qualitativa das mudanças no Oriente Médio, que podem ser fruto de uma globalização que busca a expansão de mercados, partindo-se da hipótese de que esta serve aos países mais fortes no sistema internacional, passando por cima de culturas milenares e universalizando a visão de uma região atrasada e inane.
\end{abstract}

Palavras-chave: Oriente Médio, Ocidente, Globalização e Ocidentalização.

\begin{abstract}
From the concept of perverse globalization of Milton Santos, this article analyzes the attempt to Westernization the Middle East using economic and cultural instruments to expand the boundaries of capitalism. For this, historical data will be used for a qualitative analysis of the changes in the Middle East, which may be the result of a globalization that seeks to expand markets, starting from the hypothesis that this serves the strongest countries in the international system, going over of old cultures and universalizing vision of a backward and inane region.
\end{abstract}

Keywords: Middle East, West, Globalization and Westernization.

\section{Introdução}

Utilizando o conceito de globalização perversa de Milton Santos, que relaciona as mudanças de estruturas culturais a partir da imposição de valores de um ser dominante no Sistema Internacional, o presente artigo tem como problema central a análise de diversas mudanças sociais, culturais e econômicas no Médio Oriente a partir da imposição de valores ocidentais na região. Para isso, foi analisado o conceito de globalização perversa de Milton Santos, relacionando os câmbios na sociedade daquela região, tais como inserção de empresas ocidentais e, mudanças nos hábitos culturais, com a entrada de valores alheios a região como forma de dominação da ordem regional nascente no Oriente Médio no pós-guerra fria.

Na primeira sessão foi apresentada a relação da criação da ideia do Oriente com as intervenções nesse lugar. Para isso, considerou-se o trabalho de Edward Said em Orientalismo e sua visão de construção de si a partir do outro. Também nessa sessão, expôs-se o conceito de globalização perversa de Milton Santos, a fim de dar luz às demais análises.

Na segunda sessão foi trabalhado um breve histórico da região, evidenciando as

\footnotetext{
${ }^{1}$ Ananda Vilela da Silva Oliveira é acadêmica do curso de Relações Internacionais e Integração da Universidade Federal da Integração Latino Americana na cidade de Foz do Iguaçu-PR. (ananda.vilela@ hotmail.com)
} 
intervenções francesas e inglesas num primeiro momento, e posteriormente a ingerência dos EUA. Os tratados de criação de novos Estados e as sutilezas das interferências ocidentais na região são trabalhados nessa sessão, dando o arcabouço histórico para a instrumentalização do capital trabalhada a seguir.

$\mathrm{Na}$ terceira e última sessão, buscou-se com exemplos, mostrar os efeitos da globalização na região, fez-se uma análise dos instrumentos capitalistas usados para compor as diferenças entre o antes e o depois da ocidentalização. Concretizando a hipótese de que por mais que a globalização seja entendida como benéfica pelos meios de comunicação dominantes, ela serve aos países mais poderosos no cenário internacional, que perversamente subordinam os Estados mais fracos a eles.

\section{Marco teórico e a globalização perversa}

Para que fosse possível a colonização no Oriente Médio, foi necessário não só força militar e ocupação de territórios, mas também o conhecimento sobre a cultura local, o idioma e as preferências daquela sociedade. A partir desse saber, a influência na região se tornou mais fácil, mas nem por isso menos violenta.

Por meio dessas intervenções, mais sutis ou mais incisivas, se constrói a ideia de Oriente, de fato, como uma analogia ao Ocidente, com os viajantes que iam para as terras árabes a fim de conhecer a cultura, para posteriormente inserir-se politicamente. Para Teresa Teófilo,

\footnotetext{
Há quem afirme que os portugueses criaram o primeiro orientalismo europeu a partir do século XVI. (...) as navegações marítimas portuguesas permitiram a construção de um império, não só territorial, geográfico, comercial, mas também cultural e imagético: o Oriente Português. Do contacto com culturas tão diferentes como a Índia ou a China, resultou uma construção da visão do Outro ao longo dos séculos. (TEÓFILO, 2003 apud MACEDO, 2006:08).
}

Portanto, é um conceito ocidental criado para reduzir a riqueza da cultura em relação à sua, é uma forma de conhecer e criticar, analisar e dominar. Essa dicotomia cultural se torna fonte de desentendimento, não só entre as duas civilizações diferentes, mas também no interior da região.

Nesses termos, ao estudar a concepção do Oriente por meio do conhecimento de intelectuais, - que foram chamados de Orientalistas - Edward Said põe a tona o interminável duelo que existe entre as duas culturas, opondo civilização e barbárie, progresso e retrocesso, modernização e arcaísmo, Ocidente e Oriente.

Assim, o Oriente pode ser entendido além de uma ordem geográfica num plano cartesiano, representando uma construção ocidental com bases em estereótipos que reduzem a cultura e a homogeneíza, passível agora de ser dominada por um Ocidente também idealizado (MACEDO, 2006:9).

Acerca dos estudos de Edward Said sobre a criação do Oriente, o professor Helder Alexandre Medeiros de Macedo afirma que, 
(...) trata-se de uma invenção do Ocidente, ou seja, de uma criação discursiva da Europa, com o objetivo de (re)afirmar: a) sua superioridade frente às regiões designadas como orientais, tidas como atrasadas e deslocadas no tempo e espaço; b) a identidade homogênea das populações européias, diversa da dos povos não-europeus; c) a necessidade de definição de um determinado lugar através do reconhecimento da alteridade, isto é, do Oriente (MACEDO, 2006:8).

Além disso, não só Said trabalhou a questão de invento do Oriente, mas também o sociólogo Sérgio Costa que problematizou a importância dos estudos pós-coloniais para as Ciências Sociais como um todo. Referindo-se ao Orientalismo como forma institucionalizada de produzir representações sobre a parte leste do mundo, que é confirmada e atualizada pelos conhecimentos e imagens recriados. Assim, o autor afirma que,

0 oriente do Orientalismo, ainda que remeta, vagamente, a um lugar geográfico, expressa mais propriamente uma fronteira cultural e definidora de sentido entre um nós e um eles, no interior de uma relação que produz e reproduz o outro como inferior, ao mesmo tempo em que permite definir o nós, o si mesmo, em oposição a este outro, ora representado com caricatura, ora como estereótipo e sempre como uma síntese aglutinadora de tudo aquilo que o nós não é e nem quer ser (COSTA apud MACEDO, 2006:9).

Portanto, pode-se entender que o Ocidente criou sua própria identidade em contraposição ao Oriente. Essa ideia foi consolidada pelos valores como a racionalidade, o desenvolvimento e a superioridade do lado oeste do mundo. Ao leste, atribui-se características como inferior e subdesenvolvida. Esse discurso foi em muito fomentado pela presença das três potências - França, Inglaterra e Estados Unidos - na região do Oriente Médio cada uma há seu tempo, foram esses territórios imaginativos que produziram e construíram versões do Oriente.

Nesses termos, o Ocidente considera a si próprio como superior a qualquer outra civilização existente ou que já tenho existido. Tem como base para essa afirmação dois fatores importantes para a história europeia e para o resto do mundo colonizado por eles, o Renascimento e o retorno da cultura greco-romana para a modernidade, saindo do escuro da idade média, e também a descoberta do Novo Mundo na margem oposta do Atlântico (MACEDO, 2006:13).

A partir do conhecimento de um mundo aquém do conhecido até então, surge a necessidade de discernimento e transformação do outro, por meio da religião, formas de vida, economia, política e o que for passível de mudança, isto é, inicia-se um processo de aculturação do outro.

Por isso, como efeito da dilatação da cultura ocidental pelo mundo por meio das colonizações e intervenções militares, vê-se um processo profundo de ocidentalização, ou seja, um

(...) movimento de difusão/imposição da cultura ocidental nas colônias dos Impérios Ultramarinos - em outras palavras, à conquista das almas, dos corpos e dos territórios do Novo Mundo. Esse movimento de ocidentalização, levado à frente por castelhanos e posteriormente por portugueses, produz situações de 
choque e relações de poder entre os recém-chegados (os europeus) e os que se encontravam na terra firme (os nativos). Segue mais ou menos o mesmo padrão - o da imposição da cultura ocidental sobre os modos de vida e as cosmogonias nativas -, porém, cria especificidades dependendo da porção do continente que estava sendo ocupada (MACEDO, 2006:17).

Assim, tendo em vista que a ocidentalização se inicia com a colonização, a globalização da continuação a esse sistema. 0 processo de globalização é, antes de tudo, um processo econômico e político, que consegue atingir todas as culturas e povos de forma heterogênea, e trazendo desenvolvimento desigual às diversas nações do globo.

Dessa forma, assim como o imperialismo foi uma etapa do capitalismo, a globalização está sendo mais um estágio. Esse atual momento leva o capital a territórios inimagináveis, ultrapassa fronteiras, passando por cima de valores e culturas em busca da expansão do capital financeiro. 0 desenvolvimento da produção e comércio é agora sobreposto pela financeirização da economia.

Nesses termos, Milton Santos afirma existir três mundos contidos em um. "O primeiro seria o mundo tal como nos fazem vê-lo: a globalização como fábula; o segundo seria o mundo tal como ele é: a globalização como perversidade; e o terceiro o mundo como ele pode ser: uma outra globalização" (2000:09).

Com foco da globalização perversa, entende-se que a

(...) perversidade sistêmica que está na raiz dessa evolução negativa da humanidade tem relação com a adesão desenfreada aos comportamentos competitivos que atualmente caracterizam as ações hegemônicas. Todas essas mazelas são direta ou indiretamente imputáveis ao presente processo de globalização (SANTOS, 2000:10).

Com o fim de permitir a ampliação de conhecimento no planeta, a informação funciona como um canal de saber, que se torna despótico a partir da globalização. Com a intenção de apresentar uma ideologia, a informação chega já manipulada tanto à população quanto às empresas, a fim de convencer. Ademais, é inegável perceber que as principais redes televisivas do mundo passam imagens de árabes associadas ao terrorismo (SANTOS, 2000:19).

No pós 11 de setembro, a mídia fez eco aos discursos de guerra ao terror, mas não evidenciou que o termo terrorismo foi usado ainda no governo Reagan nos EUA, com a invasão à Nicarágua e as atrocidades feitas naquele país (CHOMSKY, 2003:118). Isso acontece porque a imprensa hoje é uma máquina capitalista, que busca manter o poder político e econômico por meio de ideologias que condiciona a população.

Em entrevista em 2003, o Professor Noam Chomsky reitera a necessidade de uma mídia imparcial e democrática, que realmente informe ao invés de disseminar ideias que mantenham o status-quo. Seria necessário não demonizar, mas mostrar com clareza os fatos e discursos daqueles que fazem a guerra acontecer. ${ }^{2} \mathrm{~A}$ internet pode ocupar o lugar

\footnotetext{
${ }^{2}$ Entrevista realizada por Federico Casalegno (MIT) e traduzida por Adriana Amaral (Doutoranda do PPG-
} 
de imprensa informadora, quando proporciona uma quantidade infinitamente maior de fontes com perspectivas diferentes.

Um conceito muito difundido na era da globalização é o de "aldeia global", que faz referência à aproximação das pessoas, "um mundo só, pelas mãos do mercado global, coisas, relações, dinheiros, gostos largamente se difundem por sobre continentes, raças, línguas, religiões, como se as particularidades tecidas ao longo de séculos houvessem sido todas esgarçadas" (SANTOS, 2000:21). Dentro desse conceito, discute-se a ideia de um cidadão global, uma população desterritorializada.

Nesses termos, o pensamento de uma cidadania global não explica as medidas governamentais que restringem a entrada de imigrantes em diversos países, não explica as cotas de refugiados derivados das guerras no Oriente Médio que os países europeus estão impondo. ${ }^{3}$ Milhões de sírios são obrigados a saírem de seus lares em virtude da guerra, buscando abrigo em países que pregam a democracia, a solidariedade e a globalização como forma de aproximação dos povos e culturas, porém não os aceitam. ${ }^{4}$

Ao estudar os fatores da globalização perversa, Santos também aborda a violência do dinheiro. Em outras palavras, a monetarização da economia e a "presença do dinheiro em toda parte acaba por constituir um dado ameaçador da nossa existência cotidiana" (2000:22). Um grande exemplo dessa violência é a criação da guerra como meio de abrir mercado.

A percepção de insegurança no mundo proporcionada pela chamada Guerra contra o Terror conduzida pelos EUA, após 2001, propiciou ainda um aumento considerável na venda de armas para os países em todo o mundo. As 100 maiores empresas produtoras de armas do mundo venderam US $\$ 410$ bilhões em armas e serviços militares em 2011. Um estudo do Sipri mostra que a despesa militar no mundo, em 2011, foi de 1,6 trilhão de dólares, um aumento de $40 \%$ em 10 anos (CARTA MAIOR, 24/03/2013).

Guerra do Iraque em 2003 proporcionou aos Estados Unidos, através das ações de nation-building, contratações de:

centenas de empresas para uma gama enorme de atividades sob a rubrica "reconstrução": infraestrutura do país (sistemas de água, eletricidade, gás e transporte), escolas e hospitais; serviços de segurança aos "novos trabalhadores", treinamento das forças iraquianas e suporte logístico às operações antiterrorismo; serviços financeiros, e, naturalmente, a sua indústria petrolífera. A maior parte dos recursos foi alocada na contratação de empresas privadas de segurança. Em 2008, os dez principais fornecedores de serviços militares receberam cerca de US $\$ 150$ bilhões em contratos (CARTA MAIOR, 23/03/2013).

COM - PUCRS).

${ }^{3}$ Em setembro de 2015, a União Europeia estabeleceu cotas de 120 mil refugiados em seus territórios. (G1, 22/09/2015)

${ }^{4}$ Sete dias após o atentado a uma casa de shows em Paris (13/11/2015), a Câmara dos Representantes (equivalente à Camara dos Deputados) dos Estados Unidos aprovou por 289 votos a favor e 137 contra um projeto de lei que aumenta exigências no processo de triagem de refugiados da Síria e do Iraque. (TERRA, 19/11/2015) 
Com isso, observa-se que a globalização é um conceito construído com o intuito de transformar as populações de diversas partes do planeta em uma massa de consumo. Pode-se então, descartar todas as fantasias maravilhosas de um mundo integrado e amigável, que supõe a participação de toda sociedade nas transformações mundiais, pois essas informações não passam de fábulas (SANTOS, 2000:10).

\section{Contexto histórico e a construção do Oriente}

O Oriente Médio, berço das três religiões reveladas e de muitas civilizações, por muito tempo foi o centro do mundo, com modernas técnicas de comércio. (VISENTINI, 2012:16). Contudo, a presença ocidental na região foi limitando a sua autonomia ao longo do tempo.

A intervenção estrangeira tornou-se mais expressiva a partir do século XIX. Com França e Grã-Bretanha dominando o Canal de Suez que era passagem obrigatória para o comércio entre Europa e Ásia, e usando o Egito como trampolim para dominação de toda a região, a exploração dos recursos naturais na localidade era questão de tempo.

Nesses termos, o Irã foi de suma importância para a aproximação do ocidente com o Oriente Médio, com a criação em 1933 da Anglo Persian Oil Company, a primeira companhia a explorar petróleo na região. Posteriormente Londres também passa a tomar conta do Áden, do Kuwait, de Bahrein, de Omã e dos pequenos emirados da Península Arábica (ARANTES, 2012:1).

No início do século XX, pós-primeira guerra mundial, com a dissolução do Império Otomano, a intervenção ocidental se tornou ainda mais significativa. Com os protetorados ingleses e franceses regendo a economia, política e sociedade da região, além do período das independências. Além disso, foi nesse período que as independências eclodiram, revelando as assimetrias e as divergências culturais impostas na região.

A situação se agravou ainda mais a partir do Acordo Sykes-Picot, em 1916, entre França e Inglaterra. Esse tratado secreto preparava a divisão do Império Otomano entre as duas zonas de influência no pós-grande guerra e foi a partir deles que os Estados artificiais ${ }^{5}$ da região foram criados.

Esses territórios, submetidos a governos monárquicos favoráveis aos interesses das metrópoles, corroboraram para a manutenção da situação nos eixos por tempo que interessasse aos britânicos (ARANTES, 2012:03). Ao Reino Unido coube a Palestina, a Transjordânia e o Iraque, à França coube o Líbano e a Síria. (VISENTINI, 2012:19).

Concomitante aos acordos com os franceses, a Inglaterra também assinou tratados contraditórios com árabes e judeus. Prometendo a criação de um grande Estado Árabe,

\footnotetext{
${ }^{5}$ Em oposição ao conceito de "fronteiras naturais" que delimita os Estados a partir da divisão dos territórios por rios, montanhas ou fatores naturais que os diferem. Portanto, fronteiras artificiais podem ser entendidas como linhas imaginárias que separam os Estados, normalmente estabelecidas por acordos políticos. JERONÍMO, Patrícia. O regime internacional dos espaços. Disponível em < http://www.fup.pt/files/biblioteca/pdf/10_pdf_eqvtfg4kis2c_livro_dip_espacos.pdf>.
} 
a intenção inglesa com os árabes era conter insurgências caso houvesse contrariedade à ocupação do território turco. Já com os judeus, foi assegurado o estabelecimento da Palestina como sua terra, ganhando a simpatia da comunidade judaica e afastando o perigo da concorrência francesa.

Já para meados do século, o fim da II Guerra Mundial soma à antiga lógica do Oriente Médio novos atores centrais para a esfera internacional. Dividindo o mundo a partir de sua influência e interesse, os principais atores do momento passam a serem Estados Unidos da América e União das Repúblicas Socialistas Soviéticas.

Todavia, a promessa de um Estado judaico por parte dos ingleses ainda estava em pauta. A partir do encaminhamento da "questão palestina" à ONU, em 1948, foi criado o Estado de Israel na terra sagrada da Palestina. A situação tornou insustentável a relação entre árabes e judeus. Transformando a contrariedade aos países do ocidente em ódio, os médio-orientais veem no fundamentalismo islâmico um modo de barrar a influência ocidental nos países árabes e em seu entorno (VISENTINI, 2012:22-28).

Além disso, a Guerra Fria deixou marcas nos países ainda colonizados, que foram se rebelando contra as intervenções estrangeiras em seus territórios. A luta partia de várias frentes, a maioria de cunho nacionalista, que procuravam a autonomia de seus países. 0 domínio das antigas metrópoles se tornava mais fraco à medida que se via diretamente afetado pelas duas grandes guerras.

Assim, por volta de 1950, as nações árabes se lançavam na onda independentista, com a criação da Liga Árabe culminando em instituição pan-arabista. Ferraboli afirma que “entre os anos de 1954 e 1973, temos um Mundo Árabe recém-independente politicamente, mas não economicamente, que sofre os efeitos da Guerra Fria e que é atormentado pela difícil escolha entre soberania estatal e pan-arabismo" (2007:76).

A redefinição dos novos inimigos dos EUAno contexto do pós-guerrafria acrescentou elementos para as preocupações do país. Policiando as relações entre os Estados que se tornavam independentes, os EUA passam a representar o papel de xerife do mundo. Por conseguinte, encontraram no Oriente Médio sua fonte de recursos e forma de deixar ainda mais claro sua hegemonia não só militar, mas também política e ideológica, aumentando seu poder.

Assim, os Estados Unidos se utilizaram de mecanismos econômicos para propor um mundo livre e democrático, exportando seus valores além das fronteiras do mundo ocidental, conseguindo aliados na região que poderiam justificar as intervenções militares. A denominação de rogue states (ou Estados párias) marcou ainda mais a tentativa de dominação do Oriente Médio pela potência, possibilitando que essa dominação fosse aceita pelos demais países do Sistema Internacional, visto que agora não era somente uma intervenção comercial/financeira, era pelo bem global.

Por rogue states entendem-se países que tentavam "a busca pela obtenção e pelo desenvolvimento - ou já a posse - de Armas de Destruição em Massa (Weapons of Mass 
Destruction) e o apoio ao terrorismo" foi levada a cabo pelos dirigentes estadunidenses definindo os países que não compartilhavam de seus princípios (MIZUTA, 2012:01). Segundo o Governo Bush, esses Estados são os que

\footnotetext{
"brutalize their own people and squander their natural resources of the personal gain of the rulers, display no regard for international law, are determined to acquire weapons of mass destruction, sponsor terrorism around the globe, and reject basic human values and hate the United States and everything for which it stands." (NSSUSA 2002:13 apud MIZUTA, 2012:02).
}

Chomsky também trabalha a partir da declaração de rogue state por EUA e Inglaterra para países como Iraque: "The Washington and London declared Iraq a "rogue state," a threat to its neighbors and to the entire world, an "outlaw nation" led by a reincarnation of Hitler who must be contained by the guardians of world order, the United States and its British "junior partner". (CHOMSKY, 1994,:01) 0 autor ainda afirma que o conceito é usado para determinar países que vão em contra da dominação estadunidense, a "'rogue state" is not simply a criminal state, but one that defies the orders of the powerful-who are, of course, exempt." (CHOMSKY, 1994:16).

A partir da dita definição de inimigos no pós-guerra fria e do ataque à Nova York e Washington em 11 de setembro de 2001, o então presidente estadunidense George W. Bush discursa acerca da tentativa de criação de uma nova ordem mundial com base no interesse nacional desse país, e a guerra ao terror dava legitimidade a esse tipo de ação:

Most Americans know instinctively why we are in the Gulf. They know we
had to stop Saddam now not later. (...) They know we must make sure
that control of the world's oil resources does not fall into his hands, only
to finance aggression. They know that we know to build a new, enduring
peace, based not on arms race and confrontation but on shared principles
and the rule of law" (State of the Union, 1991 apud CASTR0, 2010:20)

Dessa forma, entende-se que o interesse ocidental no Oriente se deu por motivos econômicos na fase imperialista do capitalismo. Esse interesse teve como objetivo a expansão do mercado, isso foi alcançado por meio de diversos instrumentos, que não só possibilitaram esse aumento de consumo, mas também modificaram tradições e costumes na região.

\section{Instrumentos capitalistas na ocidentalização do Oriente Médio}

Assim, a ocidentalização passou de geração em geração, iniciando-se durante a colonização ibérica e atingindo qualquer país que sofreu intervenção ocidental posteriormente, se tratando de uma forma de dominação e controle de determinada população ou política. Com a expansão do capitalismo, tendo seus pilares no livre comércio entre as nações, o processo de ocidentalização intensificou-se ainda mais, fazendo com que as populações de diversos territórios fossem afetadas por mudanças externas, independente de suas vontades. 
A ocidentalização, que já era maléfica desde o inicio do período colonial europeu, ganhar forças com a expansão do capital estadunidense, a obtenção de lucro se torna mais importante que o bem estar da população. Isso é exatamente o que ocorre no Oriente Médio, o capital atravessou fronteiras e deixou de afetar somente os nacionais das principais potências, atingindo o mundo todo. Segundo Tavares e Belluzzo,

(...) a internacionalização do capital se dá a partir da estrutura da grande empresa, (...) e condensa todos os mecanismos interiores de expansão: mercantis, industriais e financeiros. Condensam também as práticas dos Estados imperiais anteriores, desde o impulso expansionista, até a face protecionista interna e francamente intervencionista na defesa das reservas estratégicas de matérias primas (TAVARES e BELLUZZO, 2004:116).

Dessa forma, aproveitando-se da fragilidade da população da região e também do medo da violência, os Estados Unidos usam a retórica da proteção contra a guerra ao terror e do mantimento das reservas de petróleo disponíveis para consumo, a fim de expandir seu mercado e acumular capital, usando os instrumentos da globalização, como os meios de comunicação, o cinema, a moda e as formas de vida para facilitar o trabalho.

A combinação dos instrumentos de poder é fundamental para a construção positiva dos países no Sistema Internacional. Os Estados Unidos são o maior exemplo disso, quando faz a combinação quase impecável de hard power e soft power, interagindo de maneira eficiente o seu smart power. Assim, a potência consegue "persuadir, traçar interesses em alianças, executar uma agenda internacional que lhe traga credibilidade, mantendo ou conquistando novos aliados, seja por valores políticos ou ideologias culturais" (NYE, 2010 apud BAJAA, 2015:02).

Uma das ferramentas mais utilizadas pelos Estados Unidos para invocar a opinião pública a seu favor é o cinema. Através de Hollywood, é disseminada uma visão orientalista sobre arabismo, terrorismo e islamismo, que é tida como verdade por grande parte da população ocidental. Segundo Bajaa, "a Indústria Hollywoodiana é se não o maior, o mais eficaz expoente de proliferação da cultura estadunidense ou das concepções de mundo que esta nação tem em relação às demais" (2015:19).

Em1985 e1988 estrearam os filmes Águia de Aço I eII, respectivamente, que previram a Guerra do Golfo, como forma de disseminar um sentimento antiárabe, demonizando mulçumanos, fazendo com que os mesmos recebessem tratamento diferenciado onde estivessem (BAJAA, 2015:04). Hollywood não cessou seus investimentos na criação de filmes que indispõem culturas e civilizações, produções como Nova York Sitiada (1998), Borat (2007), Guerra ao Terror (2010), Argo (2012), A Hora mais Escura (2013) e Sniper Americano (2015) que tiveram grande apreço da academia, expõem a visão genérica e hostil dos estadunidenses para com os árabes. ${ }^{6}$

Por meio desses filmes, os orientais em geral, e os árabes e mulçumanos em particular, são mostrados com estereótipos construídos, nunca como cidadãos civis entendidos

\footnotetext{
${ }^{6}$ Todos os filmes foram encontrados em resenhas do site < http://www.adorocinema.com/>.
} 
como normais, mas como desajustados socialmente, interessados apenas em suicídio e forma de causar a morte de demais pessoas, semeando o ódio e desavença por meio da cultura. 0 enredo maniqueísta, dividido entre o lado bom e o ruim da história, cria certa empatia com os soldados estadunidenses e antipatia aos árabes, a quem não é dado o direito de voz. A estratégia de falar pelo outro é mais uma forma de aculturação, tomandoos como incapazes de contar sua própria versão da história, consegue-se a imposição do pensamento ocidental.

A moda também exerce papel importante na ocidentalização do Oriente Médio como forma de homogeneização de uma cultura baseada no consumo de massa e nos processos de globalização. A roupa não tem só a função de proteção do corpo contra frio e umidade, mas desempenha também o papel de indicar uma identidade, uma origem ou forma de vida (SASAKI, 2010:03).

No entanto, é comum encontrar nas cidades do Oriente Médio, homens sentados em cafés, vestidos com calça jeans e camiseta, vestimentas muito distintas das que marcaram suas culturas durante séculos e que se assemelha do vestuário ocidental. Embora os homens estejam, em relação às roupas, acompanhando as tendências ocidentais, a maioria das mulheres ainda continua usando as tradicionais burcas ou hijab, sendo excluídas das mudanças no mundo fashion (SASAKI, 2010:02).

Ainda que a ocidentalização da moda esteja atingindo uma parte da população oriental, ela não é maioria, visto que as classes mais abastadas são as que têm acesso ao consumo de tais produtos, afastando as mudanças de grande parte do povo. As modificações no vestuário oriental, feminino principalmente, não se dão explicitamente nas roupas, mas sim nos acessórios e sapatos, que não são rechaçados em suas próprias sociedades, ou seja, mesma que tenha imposição da cultural ocidental e certa abertura por parte daquela sociedade, ainda se tem resguardo com algumas características das culturas milenares.

Não somente as roupas são de acesso das classes mais altas, mas também as formas de vida e consumo ocidentais internacionalizadas, como a alimentação. Segundo Santos, o

(...) alimento constitui uma categoria histórica, pois os padrões de permanência e mudanças dos hábitos e práticas alimentares têm referências na própria dinâmica social. Os alimentos não são somente alimentos. Alimentar-se é um ato nutricional, comer é um ato social, pois constitui atitudes ligadas aos usos, costumes, protocolos, condutas e situações. Nenhum alimento que entra em nossas bocas é neutro. A historicidade da sensibilidade gastronômica explica e é explicada pelas manifestações culturais e sociais, como espelho de uma época e que marcaram uma época. Nesse sentido, o que se come é tão importante quanto quando se come, onde se come, como se come e com quem se come (SANTOS, 2006:1).

A internacionalização da comida compartimentada, ou fast food, se dá por meio da McDonald's Corporation, que exporta seus restaurantes pelo mundo todo. Como resultado, diferem a forma alimentar dos lugares onde está presente, impondo sua 
dominação alimentar em termos econômico, social, político e cultural, baseada em uma grande explosão de consumo. “Desde 1993, os países do Oriente Médio cedem ao Império Mcdonald, sendo que se estendeu neste ano para Israel e Arábia Saudita, e no ano seguinte, em 1994, invadiu o Egito, o Bahrein e os Emirados Árabes" (SANTOS, 2006:09). Apesar de a modificação alimentar ser imposta, isso de certa forma é aceito e internalizado como forma de diferenciação, "o que lhe traz a distinção e que lhe permite a mudança do estatuto sócio econômico e cultural” (BOURDIEU, 1979 apud SANTOS, 2006:03). Também é necessário entender que o problema vai além da imposição alimentar, com a internacionalização das grandes corporações, fortalecendo grandes monopólios e "constituindo um império estandardizado sobre o(s) seu(s) produto(s), suas matérias primas, seus modos de produção, de comercialização e de consumo" (SANTOS, 2009:03).

Na década de 90, um colunista do New York Times desenvolveu a Teoria dos Arcos Dourados, na qual afirma que os países que possuem McDonalds não guerreiam entre si. Em exemplos como Líbano, Jordânia e Arábia Saudita, que se abriram para a rede de fast food, e Síria, Irã e Iraque, que não tem o restaurante em seus territórios, vê-se que a teoria tem certa veracidade, uma vez que, os três primeiros não conflitam entre si, em diferença de Irã e Iraque tem sérias contradições e desavenças (SARFATI, 2005:102).

Todavia, a afirmação de que as guerras entre os possuidores de McDonalds não aconteceu é uma analogia à inserção do capitalismo nessas sociedades, mas seria certo afirmar que o capitalismo impede conflitos? Não, apesar de não lutarem entre si, diversos países capitalistas, inclusive esses já citados, financiam guerras contra Estados inimigos, quando não declaram combate diretamente.

Em síntese, a sociedade árabe está passando por modificações cada vez mais contundentes não só na sua forma de alimentar-se e vestir-se, mas também na forma de se portar frente à importação de inovações ocidentais na região. Observa-se que a aceitação da aculturação parte, principalmente, das classes mais altas, não atingindo a totalidade da população, mas que está mudando lenta e profundamente culturas milenares.

\section{Considerações Finais}

Em suma, entendendo a globalização como uma nova fase do desenvolvimento do capitalismo, que nas palavras de Vilas, faz parte de um processo

(...) multissecular de expansão do capitalismo desde suas origens mercantis em algumas cidades da Europa nos séculos XIV e XV. Como tal, é parte integrante de um modo de organização econômica e social profundamente desigualador, baseado na exploração dos seres humanos e na depredação da natureza: um modo de organização social e econômica que associa o progresso de alguns com as desventuras de muitos; o êxito com o desalento; a abundância com o empobrecimento (VILAS, 2008:23).

Conclui-se que os meios utilizados pelas potencias hegemônicas em seus períodos 
de notoriedade, foram usados para que seus interesses fossem alcançados de diferentes formas, sob lentes sutis como a internacionalização de fast foods ou mais violentas como trabalhadas no texto, transformando a realidade da sociedade do Oriente Médio.

A irradiação de uma imagem de árabes violentos e sedentos por mortes de infiéis legitima as intervenções militares no Oriente Médio, que tem como objetivo final a dominação da região, proporciona a abertura do mercado regional ao capital estadunidense. Um agravante dessa situação é a veiculação pela internet de vídeos com terroristas torturando ocidentais ou simpatizantes dos mesmos, ou seja, essa ação de grupos extremistas acaba por corroborar a imagem vendida no mundo todo pelo interesse do capital hegemônico.

Por meio dos estudos de Said e de dados históricos, foi possível perceber que não é um evento recente a ocidentalização no Oriente Médio. França e Inglaterra iniciaram o processo em meados do século XIX, ocupando o local durante anos, tendo em vista que aproveitaram de sua fragilidade social e econômica, dividindo o território a seu bel prazer. Em seu período de glórias, os dois países abusaram economicamente do território, levando a "modernidade" para eles em troca de recursos naturais estratégicos.

Atualmente, com a redução da força dos países europeus, a preponderância estadunidense nesses países é marcante, seja por meio de intervenções militares, como no caso do Iraque - que posteriormente passou a ser também através de empresas transnacionais - ou por meio de coalizões, como os casos da Arábia Saudita e Israel, que representam desde o inicio da presença estadunidense os principais aliados na região.

Portanto, como o propósito final desse artigo, considera-se que a globalização é um conceito construído sob a farsa da integração, que na verdade serve aos interesses das principais potências mundiais, notadamente os Estados Unidos.

\section{Bibliografia}

ARANTES, José Tadeu, (Kabir). A invenção do Oriente Médio. Disponível em: <https:// josetadeuarantes.wordpress.com/2012/04/10/a-invencao-do-oriente-medio/>. Acesso em: 17 Nov. 2015.

BAJAA BAJAA, Ashraf Abdul Jabbar. Construção hollywodiana de um mundo antiárabe: o desconcerto de "Nova York Sitiada" sob um xadrez teórico. NOVAS FRONTEIRAS: - v.2 n.1 (Jan-Jun) 2015. Revista Acadêmica de Relações Internacionais da ESPM-Sul. Disponível em < http://novasfronteiras.espm.br/index.php/RNF/article/view/41>. Acesso em 18 Nov. 2015.

BELLUZZO, L. G. M. ; TAVARES, M. C. . A mundialização do capital e a expansão do poder americano. In: José Luís Fiori. (Org.). O poder americano. 1ed. Petrópolis: Vozes, 2004, p. 111-138

CASTRO SANTOS, Maria Helena. 0 papel dos Estados Unidos na Nova Ordem 
Internacional e as intervenções militares americanas no pós-Guerra Fria: que lugar ocupa aí a democracia?. Boletim Meridiano 47, No. 117, 2010, p. 18 a 22. Disponível em: < http://periodicos.unb.br/index.php/MED/article/view/436/259>. Acesso em 17 Nov. 2015.

O Processo de Democratização da Terceira Onda de Democracia: quanto pesam as variáveis externas?. Boletim Meridiano 47, No. 115, 2010, p. 15-18. Disponível em <http://periodicos.unb.br/index.php/MED/article/view/467/281>. Acesso em 17 Nov. 2015.

CHOMSKY, Noam. Mídia, terrorismo e (des)informação. Revista FAMECOS • Porto Alegre - no 22 • dezembro 2003, p. 117-125. Disponível em < http://revistas.univerciencia.org/ index.php/famecos/article/viewFile/239/183>. Acesso em 19 Nov. 2015.

Rogue States. Z Magazine, April, 2994. Disponível em < https://chomsky. info/199804_/>. Acesso em 01 Ago. 2016.

FERRABOLI, Silvia. Relações Internacionais do Mundo Árabe (1954-2004): Os Desafios para a Realização da Utopia Pan-arabista. CONTEXTO INTERNACIONAL - vol. 29, no 1, jan/jun 2007, p. 63-97.

FOLHA. Ataques coordenados aterrorizam Paris e deixam 129 mortos. 13 de Novembro de 2015. Disponível em <http://www1.folha.uol.com.br/mundo/2015/11/1706236policia-francesa-registra-tiroteio-e-explosao-em-paris.shtml>. Acesso em 19 Nov. 2015.

FORBES BRASIL. Entenda em 10 minutos como nasceu a crise no Oriente Médio, que chegou à França. 16 de Novembro de 2015. Disponivel em < http://www.forbes.com.br/ videos/2015/11/entenda-em-10-minutos-como-nasceu-a-crise-no-oriente-medio-quechegou-a-franca/>. Acesso em 19 Nov. 2015.

G1. Ministros da UE entram em acordo para divisão de cotas de refugiados. 22 de Setembro de 2015. Disponível em < http://g1.globo.com/mundo/noticia/2015/09/ ministros-da-ue-entram-em-acordo-para-divisao-de-cotas-de-refugiados.html>. Acesso em 19 Nov. 2015.

HALLIDAY, Fred. The Middle East in International Relations: Power, Politics and Ideology. Nova Iorque: Cambridge University Press, 2005.

KAMRAVA, Mehran. The modern Middle East: a political history since the First World War. University of California Press, 2005.

MACEDO, Helder Alexandre Medeiros de. Oriente, Ocidende e Ocidentalização: discutindo conceitos. Revista da Faculdade do Seridó, v.1, n. 0, jan./jun.2006.

MIZUTA, Karen Katarine. Rogue States: o conceito e sua utilização sob a ótica construtivista. IV Congresso Uruguaio de Ciência Política "A Ciência Política desde o Sul". Associação Uruguaia de Ciência Política, 2012. Disponível em <http://www.aucip.org.uy/ docs/cuarto_congreso/13122415\%20-\%20Mizuta,\%20Karen.pdf>

NASSER, Reginaldo Mattar. Iraque dez anos depois: a guerra é um grande negócio!. 
São Paulo, 24 de marços de 2013. Disponível em < http://cartamaior.com.br/?/Editoria/ Internacional/Iraque-dez-anos-depois-a-guerra-e-um-grande-negocio-/6/27750>. Acesso em 19 Nov. 2015.

PRETO, Afonso Ouro. Oriente Médio. In: 0 Brasil no mundo que vem aí / I Conferência Nacional de Política Externa e Política Internacional, Rio de Janeiro, 6 e 7 de julho de 2006. - Brasília : Fundação Alexandre de Gusmão, 2007. p. 305-316. Disponível em < http:// www.funag.gov.br/biblioteca/dmdocuments/0452.pdf>. Acesso em 19 Nov. 2015.

SAID, Edward. Orientalismo: o Oriente como invenção do Ocidente. $1^{\underline{a}}$ ed. Companhia das Letras. São Paulo, 2007.

SANTOS, Carlos Roberto Antunes dos. O Império do Mcdonalds e a Mcdonalização da Sociedade: Alimentação, Cultura e Poder. Seminário Facetas do Império da Historia. Paraná, 2006. Disponível em < http://people.ufpr.br/ andreadore/antunes.pdf>. Acesso em 19 Nov. 2015.

SANTOS, Milton. Por uma outra globalização - do pensamento único à consciência universal. São Pauto: Record, 2000.

SARFATI, Gilberto. Teoria das relações internacionais. São Paulo: Saraiva, 2005.

SASAKI, Silvia. Moda no Médio Oriente: Aspectos Históricos e Culturais sob Influência Ocidental. 6o Colóquio de Moda. 3a edição internacional. São Paulo - SP, 2010. Disponível em <http://www.coloquiomoda.com.br/anais/anais/6-Coloquio-de-Moda_2010/71317_ Moda_no_Medio_Oriente_-_aspectos_historicos_e_culturai.pdf >. Acesso em 18 Nov. 2015.

TERRA. Cresce pressão para que EUA rejeitem refugiados sírios. 19 de Novembro de 2015. Disponível em <http://noticias.terra.com.br/mundo/cresce-pressao-para-queeua-rejeitem-refugiados-sirios,d57c55e708dde61c0f452bf2d21299b8vuwdt192.html> . Aceso em 19 Nov. 2015.

VILAS, Carlos M. Seis idéias falsas sobre a globalização. Estudos de sociologia, v. 4, n. 6, 2008, p. 21-61. Disponível em < http://seer.fclar.unesp.br/index.php/estudos/article/ viewFile/749/614>. Acesso em 19 Nov. 2015. 